\title{
The Role of Carnitine in Acetoacetate Production and Fatty Acid Synthesis *
}

\author{
Rubin Bressler $\dagger$ AND Richard I. Katz \\ (From the Department of Medicine, Duke University Medical Center, Durham, N. C.)
}

In recent years a number of investigators have obtained evidence which supports the hypothesis that carnitine ( $\gamma$-trimethylammonium $\beta$-hydroxybutyrate) serves as a carrier of activated fatty acyl groups across the mitochondrial barrier (1-5). Because of the impermeability of the mitochondrial barrier to fatty acyl $\mathrm{CoA}(1,6,7)$ it was postulated that carnitine esters of fatty acids are the form in which the activated acyl groups are transported across the mitochondrial barrier. The formation of the carnitine esters of the activated acyl group is shown in Equation 1.

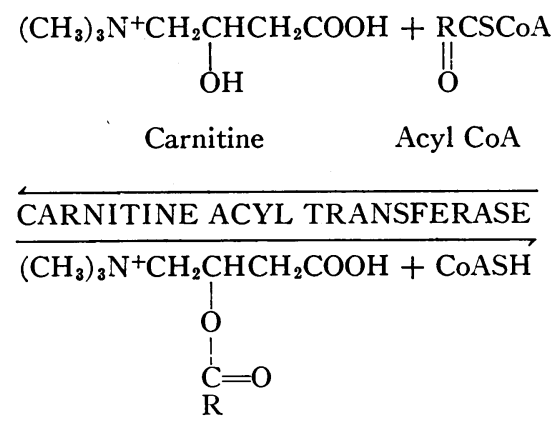

Acylcarnitine

In its proposed transport function, carnitine might participate in the movement of two classes of fatty acyl CoA derivatives: 1 ) the movement of long-chain fatty acyl CoA from the microsomal and cytoplasmic fractions where they are formed (8) to the mitochondria where they are oxidized (9) and 2) the movement of acetyl CoA or acetoacetyl

\footnotetext{
* Submitted for publication July 21, 1964; accepted January 21, 1965.

This work was supported by U. S. Public Health Service grants HE 7061 and M-01-FR 3003 and a grant from the American Heart Association (64-G116).

Presented in part at the Fifty-sixth Annual Meeting of the American Society for Clinical Investigation, Atlantic City, N. J., May 1964.

† Address requests for reprints to Dr. Rubin Bressler, Clinical Research Unit, Duke University Medical Center, Durham, N. C.
}

CoA from the mitochondria where they are formed to extramitochondrial sites of long-chain fatty acid synthesis (10).

It has been previously observed that carnitine stimulates the production of acetoacetate in rat liver homogenates (11). The data to be presented in this communication suggest that in the ketosis of fasting the stimulatory effect of carnitine on acetoacetate production by the liver might be attributed to two factors both of which are related to the transport function of carnitine. These factors are: 1) an increased rate of movement of long-chain fatty acyl groups into the mitochondria for oxidative conversion to acetoacetyl $\mathrm{CoA}$, and 2) an increased rate of transport of acetoacetyl groups out of the mitochondria as carnitine derivatives. As a corollary it will be shown that in liver homogenates from nonfasted animals, carnitine decreases acetoacetate production and stimulates long-chain fatty acid synthesis.

\section{Materials}

Pregnant guinea pigs in the third trimester, weighing 600 to $700 \mathrm{~g}$, were used in the experiments on acetoacetate production. Pregnant animals were used because they become considerably more ketotic in the fasted state than nonpregnant fasted guinea pigs. To produce ketosis, the animals were fasted for 24 hours. Paired control animals were maintained on a standard diet consisting of $50 \%$ Purina rabbit chow and $50 \%$ oats supplemented with fresh cabbage. In the experiments on long-chain fatty acid synthesis, male guinea pigs weighing 250 to $300 \mathrm{~g}$ were used. These animals were fed the aforementioned diet.

The in vitro incubations were carried out with whole liver homogenates prepared in 6 vol of Krebs-Ringer phosphate buffer, $\mathrm{pH} 7.4$, or with liver mitochondria prepared by the method of Schneider and Hogeboom (12).

Acetoacetate was determined colorimetrically both in liver homogenates and serum by the procedure of Walker (13). Blood acetoacetate in the fasted guinea pigs ranged from 10.8 to $14.2 \mathrm{mg}$ per $100 \mathrm{ml}$, whereas the levels in the fed group were from 2.0 to $3.6 \mathrm{mg}$ per $100 \mathrm{ml}$. There were six animals in each group. Net 
acetoacetate production was determined by substracting the acetoacetate present before incubation. The specific activity of the acetoacetate produced from labeled precursors was determined by the procedure of Sauer (14). In this procedure the acetoacetate formed is reacted with diazotized $p$-nitroaniline and the radioactivity of the resultant formazan derivative of acetoacetate measured. Quantitative recoveries of the $\mathrm{C}^{14}$ activity in C3 of acetoacetate were obtained with this method. The radioactive acetoacetic formazan derivative was extracted with ethyl acetate, washed five times with water, plated on glass cover slips, and assayed with a Nuclear-Chicago gas flow counter.

The synthesis of fatty acids was measured by the extent to which pyruvate-2-C $\mathrm{C}^{14}$ was incorporated into longchain fatty acids by the liver homogenates. At the end of the incubation period the reaction was stopped by the addition of $2.5 \mathrm{ml}$ of $10 \%$ methanolic $\mathrm{KOH}$ and the mixture put into a boiling water bath for 30 minutes. The mixture was then brought to $\mathrm{pH} 2$ to 3 by the addition of $125 \mathrm{ml}$ of $4 \mathrm{~N} \mathrm{HCl}$, and then extracted four times for 3 minutes with $5-\mathrm{ml}$ portions of $\mathrm{n}$-pentane. The pooled pentane extracts were concentrated under a stream of nitrogen to a final volume of $0.5 \mathrm{ml}$. Samples of the pentane extract were counted in $10 \mathrm{ml}$ of a phosphor solution consisting of toluene containing 2,5-diphenyloxazole (4 g per L) and 1,4-bis-2-(5-phenyloxazolyl)benzene (100 mg per L) in a Packard Tri-Carb liquid scintillation spectrometer. The $C_{10}$ to $C_{18}$ fatty acids are extracted by this procedure (15).

Assay of fatty acid oxidations was carried out as previously described (16)

Carnitine and acylcarnitine derivatives were separated by thin layer chromatography. Basic silica gel plates were prepared according to procedures described by Skipski, Peterson, and Barclay (17) and developed in chloroform : methanol : ammonia : water (50:40:4:4). Standards of carnitine, acetylcarnitine, acetoacetyl CoA, and acetyl $\mathrm{CoA}$ were used. The acylcarnitine derivatives ran ahead of carnitine, whereas coenzyme $A$ and the coenzyme $A$ derivatives remained at the origin. The separated bands were visualized by exposure to iodine vapors.

Radioactive acetylcarnitine was isolated from the aqueous phase of the lipid extracted reaction mixtures. The aqueous phase was dried under vacuum and taken up in $0.5 \mathrm{ml}$ absolute ethanol to which $10 \mathrm{mg}$ of acetylcarnitine had been added and dissolved. The dissolved acetylcarnitine was then crystallized by the successive additions of acetone : diethyl ether $(5 \mathrm{ml}: 10 \mathrm{ml}$ ) according to the procedure of Bremer (18). The twice recrystallized product was dried, weighed, and shown to be chromatographically pure by thin layer chromatography. The melting point (186 to $188^{\circ}$ ) confirmed the purity of the product. A 1-mg portion of the acetylcarnitine precipitate was then assayed for radioactivity.

For quantification of lipid in the liver the homogenates were extracted by the method of Folch and associates (19), and triglycerides were determined by the procedure of van Handel and Zilversmit (20).
Protein content of the homogenate and mitochondria was measured by the biuret method (21). After completion of the biuret reaction the solution was filtered through a layer of Celite in a Buchner type funnel. This was necessary to remove lipids that produced turbidity of the solution, especially in the ketotic animals. The results obtained by this procedure agreed closely with those obtained by Kjeldahl nitrogen determinations (22).

The short-chain acyl CoA-carnitine acyltransferase was prepared from beef heart by the procedure of Fritz, Schultz, and Srere (23). The preparation had a specific activity of $0.68 \mu$ mole per $\mathrm{mg}$ protein per minute at $30^{\circ}$ and $\mathrm{pH}$ 7.4. It exhibited traces of acetyl CoA hydrolase activity, but was virtually free of thiolase activity. The assay for thiolase activity is shown in Table $\mathrm{V}$ of the results. Thiolase was prepared from pig heart by the procedure of Stern (24). It had a specific activity of $1.3 \mu$ moles acetoacetyl CoA cleaved per $\mathrm{mg}$ protein per minute at $25^{\circ}$ at $\mathrm{pH}$ 8.0. The assay was followed spectrophotometrically as a decrease in the absorption of acetoacetyl $\mathrm{CoA}$ at $305 \mathrm{~m} \mu$ (24). Magnesium ions were added to enhance the absorption of the enolate ion of the $\beta$-ketoester (24). $\mathrm{L}(+) \beta$-hydroxyacyl CoA dehydrogenase ${ }^{1}$ was prepared from beef liver and had a specific activity of $3.8 \mu$ moles per $\mathrm{mg}$ protein per minute at $35^{\circ}$ at $\mathrm{pH} 6.5$ (25).

Acetoacetylcarnitine was chemically prepared from acetoacetylfluoride and carnitine in the presence of an acid catalyst. Acetoacetylfluoride was prepared by the method of Olah and Kuhn (26). The reaction mixture contained 30 mmoles acetoacetylfluoride, 5 mmoles carnitine hydrochloride, and 0.05 mmole of perchloric acid in $75 \mathrm{ml}$ of tetrahydrofuran. The reaction proceeded at $25^{\circ}$ for 8 hours with stirring. The solvent was removed under vacuum and the residual thick yellow oil taken up in methanol. The acylcarnitine was crystallized from methanol : acetone: diethyl ether $(1: 5: 20)$ by the procedure of Bremer (18). The resulting white crystals were dried and infrared absorption spectroscopy done in a $\mathrm{KBr}$ pellet. The compound showed the presence of an ester band at $1,720 \mathrm{~cm}^{-1}$, a $\beta$-ketoester band at $1,735 \mathrm{~cm}^{-1}$, and did not show an absorption band in the $3,600 \mathrm{~cm}^{-1}$ region where the alcohol group of carnitine has a characteristic absorption band.

When the acetoacetylcarnitine was run on a thin layer chromatogram (17), it had an $R_{f}$ similar to that of acetylcarnitine. Hydrolysis of the acylcarnitine in methanolic $\mathrm{KOH}$ resulted in its conversion to acetoacetate and carnitine.

Acetyl CoA and acetoacetyl CoA were prepared as previously described (27). Carnitine, acetylcarnitine, and $\boldsymbol{\gamma}$-butyrobetaine ( $\boldsymbol{\gamma}$-trimethylammonium butyrate) ${ }^{2}$ radioactive pyruvate-2- $C^{14}$ and acetoacetate- $3-C^{14} ; 3$ C $C^{14}$ -

1 Gift of Dr. S. J. Wakil of the Biochemistry Department.

2 California Corporation for Biochemical Research, Los Angeles, Calif.

${ }^{3}$ New England Nuclear Corp., Boston, Mass. 
methyl-labeled carnitine; $\mathbf{4}$ and neatan (a dispersion of polyvinylproprionate) ${ }^{5}$ were obtained commercially.

\section{Results}

The effect of carnitine on acetoacetate production. In liver homogenates from fasted guinea pigs carnitine increased the rate of acetoacetate production twofold, whereas in homogenates from control fed animals carnitine resulted in a decreased rate of acetoacetate production (Table I).

Table I also shows the decrease in specific activity of acetoacetate that resulted from the addition of carnitine to liver homogenates from both fasted and fed guinea pigs. The decrease in specific activity of the fasted preparations is highly significant $(p<0.01)$, whereas the decrease in the fed preparations is of borderline significance $(p=$ $0.05)$. The decrease in specific activity of acetoacetate effected by carnitine in the fasted preparation suggested that the augmented rate of acetoacetate production in the presence of exogenous

4 Tracerlab, Waltham, Mass.

5 E. Merck, Darmstadt, Germany. carnitine originated from an endogenous substrate whose metabolism was influenced by carnitine rather than from the labeled pyruvate added to the incubation mixture. Since the oxidation of longchain fatty acids has been shown to be accelerated by carnitine $(1,4,11)$, extramitochondrial longchain fatty acids could have served as the source of the additional unlabeled acetoacetate. This possibility was supported by triglyceride analyses of the livers. The triglyceride content of the livers of a group of six fasted guinea pigs ranged from 8.3 to $14.1 \mathrm{mg}$ per $\mathrm{g}$ wet weight liver, whereas a control group of six ranged from 2.3 to $3.8 \mathrm{mg}$ per $\mathrm{g}$. This is consistent with the established correlation between ketosis and the quantity of triglyceride in the liver (28).

In an attempt to ascertain the role of the extramitochondrial triglyceride in the carnitine effects of acetoacetate production in the fasted liver preparation ( $c f$. Table I), mitochondria from fasted guinea pig livers were used. The use of twice washed mitochondria in the reaction mixture served to minimize the extramitochondrial tri-

TABLE I

Effect of carnitine on acetoacetate production*

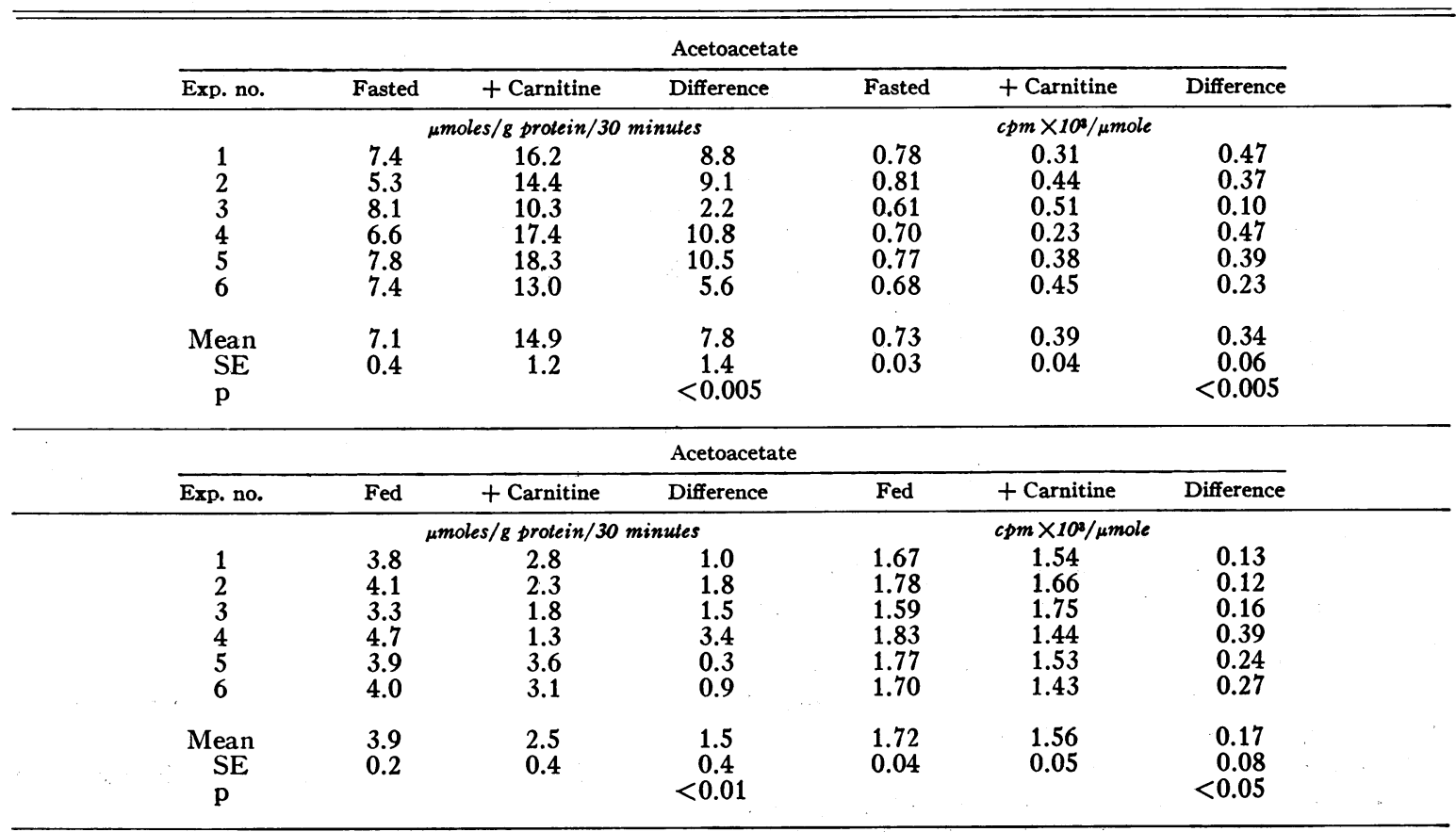

* The reaction mixtures contained $20 \mu$ moles of pyruvate- $2-C^{14}\left(2 \times 10^{6} \mathrm{cpm}\right)$ and between 38 and $47 \mathrm{mg}$ of liver homogenate in $2 \mathrm{ml}$ of calcium-free Krebs-Ringer phosphate buffer, $\mathrm{pH} 7.4$. Five $\mu$ moles of DL-carnitine was added where indicated. Final reaction volumes were $2.2 \mathrm{ml}$. Incubations were at $37^{\circ}$ for 30 minutes. 
TABLE II

Effect of carnitine on mitochondrial acetoacetate production*

\begin{tabular}{|c|c|c|c|c|c|c|}
\hline \multicolumn{7}{|c|}{ Acetoacetate } \\
\hline Exp. no. & Control & + Carnitine & Difference & Control & + Carnitine & Difference \\
\hline & \multicolumn{3}{|c|}{$\mu$ moles $/ 5 \mathrm{mg}$ protein } & \multicolumn{3}{|c|}{ cpm $\times 10^{3} / \mu$ mole } \\
\hline 1 & 0.71 & 1.28 & 0.57 & 1.13 & 0.94 & 0.19 \\
\hline 2 & 0.55 & 0.83 & 0.28 & 1.08 & 1.12 & -0.04 \\
\hline 3 & 0.31 & 0.78 & 0.47 & 0.96 & 0.90 & 0.06 \\
\hline 4 & 0.63 & 0.98 & 0.35 & 0.88 & 0.98 & -0.10 \\
\hline Mean & 0.55 & 0.97 & 0.42 & 1.01 & 0.99 & 0.03 \\
\hline $\mathrm{SE}$ & 0.09 & 0.11 & 0.07 & 0.06 & 0.05 & 0.06 \\
\hline $\mathrm{p}$ & & & $<0.005$ & & & $<0.40>0.30$ \\
\hline
\end{tabular}

* The reaction mixtures all contained $20 \mu$ moles of pyruvate-2-C $\mathrm{C}^{14}\left(10^{6} \mathrm{cpm}\right), 5 \mu$ moles ATP, $4 \mathrm{mg}$ bovine serum albumin, $1 \mu$ mole sodium succinate, and between 4.5 and $9.7 \mathrm{mg}$ of fasted guinea pig liver mitochondria in $1 \mathrm{ml}$ of calciumfree Krebs-Ringer phosphate buffer, $\mathrm{pH}$ 7.4. Four separate incubations were run. These incubations were both without and with the addition of $5 \mu$ moles of DL-carnitine. Final incubation volumes were $1.3 \mathrm{ml}$. Incubations were at $30^{\circ}$ for 15 minutes.

glyceride reservoir of long-chain fatty acids. The effect of carnitine on the conversion of pyruvate$2-\mathrm{C}^{14}$ to acetoacetate was assayed in order to evaluate the possible role of carnitine in transporting activated acetoacetyl groups, derived from pyruvate$2-\mathrm{C}^{14}$, out of the mitochondria. Table II shows that carnitine resulted in a stimulation of acetoacetate production by the mitochondria but no consistent change in the specific activity of the acetoacetate. These data suggested an effect of carnitine on the conversion of pyruvate to acetoacetate. Because it had been suggested that the short-chain acyl CoA-carnitine acyltransferase might serve to transport short-chain acyl CoA from intra- to extramitochondrial sites $(2,5)$, it was thought possible that carnitine might play a role in the transport of activated acetoacetyl groups, formed from pyruvate in the mitochondria, to extramitochondrial sites of acetoacetate formation.

Some further evidence that demonstrates the importance of the role of carnitine in acetoacetate production is given in Table III. $\gamma$-Butyrobetaine, a competitive inhibitor of carnitine $(29,30)$, markedly depressed the production rate of acetoacetate in the fasted liver homogenate. This depression of acetoacetate production was reversed by increasing amounts of carnitine.

Detection of acetoacetylcarnitine. In an attempt to ascertain the role of carnitine in acetoacetate production the detection of acetoacetylcarnitine in the fasted guinea pig liver homogenate was undertaken.

When methyl-labeled $\mathrm{C}^{14}$-carnitine was used in a typical reaction mixture, two radioactive peaks were found (Figure 1). Peak 1 was identified as carnitine both by $R_{f}$ on thin layer chromatography and by enzymatic assay (31). In this thin layer chromatography system, coenzyme A, acetyl CoA, and acetoacetyl CoA remained at the origin, whereas carnitine (peak 1) had an $R_{f}$ of about 0.40 , and peak 2 had an $R_{f}$ of about 0.60 . Peak 2 contained about $10 \%$ ( $1 \mu$ mole) of the $\mathrm{C}^{14}$ carnitine counts present in the reaction mixture and had an $R_{f}$ similar to that of an acetylcarnitine standard. Only faint traces of free carnitine were found by enzymatic assay (maximum of $5 \%$ of peak 2), but after 30 minutes of alkaline hydrolysis, high carnitine activity was present. It was concluded that peak 2 probably consisted of acylcarnitines, possibly containing acetoacetylcarnitine.

TABLE III

Effect of $\gamma$-butyrobetaine on the production of acetoacetate*

\begin{tabular}{lc}
\hline \multicolumn{1}{c}{ Reaction } & Acetoacetate \\
\hline & $\mu$ moles $/ \mathrm{g}$ \\
& protein $/ 30$ \\
& minutes \\
1. Pyruvate & 6.4 \\
2. Pyruvate + carnitine $10^{-3} \mathrm{M}$ & 17.3 \\
3. Pyruvate $+\gamma \mathrm{BB} 10^{-2} \mathrm{M}$ & 2.2 \\
4. Pyruvate $+\gamma \mathrm{BB} 10^{-2} \mathrm{M}+$ carnitine $10^{-3} \mathrm{M}$ & 4.8 \\
5. Pyruvate $+\gamma \mathrm{BB} 10^{-2} \mathrm{M}+$ carnitine $3 \times 10^{-3} \mathrm{M}$ & 10.2 \\
6. Pyruvate $+\gamma \mathrm{BB} 10^{-2} \mathrm{M}+$ carnitine $5 \times 10^{-3} \mathrm{M}$ & 18.8 \\
\end{tabular}

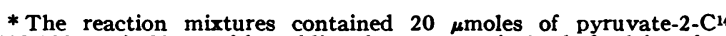
$(400,000 \mathrm{cpm}), 32 \mathrm{mg}$ of fasted liver homogenate in $2 \mathrm{ml}$ of calcium-free

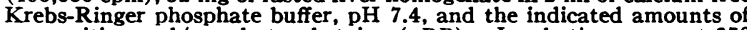
DL-carnitine and/or $\gamma$-butyrobetaine $(\gamma \mathrm{BB})$. Incubations were at $37^{\circ}$ for 30 minutes. 


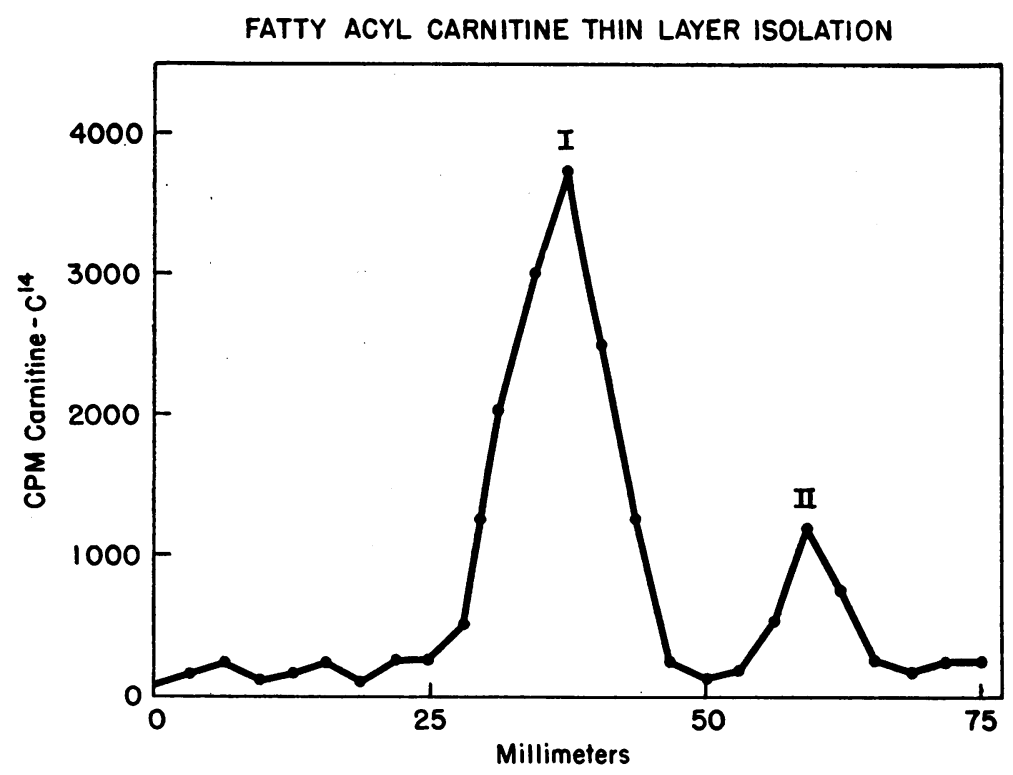

Fig. 1. Thin layer chromatography isolation of aCetoacetylcarniTINE. The reaction mixture contained $40 \mu$ moles pyruvate, $10 \mu$ moles $C^{14}$ methyl-labeled carnitine $\left(8 \times 10^{8} \mathrm{cpm}\right)$, and $40 \mathrm{mg}$ of fasted guinea pig liver homogenate in $2.5 \mathrm{ml}$ of calcium-free Krebs-Ringer phosphate buffer, $\mathrm{pH} 7.4$. Final reaction volume was $2.8 \mathrm{ml}$. Incubation was at $37^{\circ}$ for 1 hour. The reaction was terminated with $1 \mathrm{ml}$ of $20 \%$ perchloric acid and the resultant supernatant neutralized with $\mathrm{KOH}$. The supernatant volume was reduced to $0.5 \mathrm{ml}$ under vacuum, and plated on a basic silica gel $\mathrm{H}$ thin layer chromatography plate (17). The plate was developed in chloroform: methanol: ammonia: water $(50: 40: 4: 4)$. Standards of carnitine and acetylcarnitine were run. The chromatography plate was sprayed with neatan and a $1-\mathrm{cm}$ strip of the plate was divided into $3-\mathrm{mm}$ sections. These sections were scraped off the plate with a spatula and placed in vials for scintillation counting. The results are shown in this figure.

An attempt was made to detect the presence of acetoacetylcarnitine in peak 2 .

An aqueous extract of peak 2 was reacted with coenzyme $\mathrm{A}$ in the presence of acyl CoAcarnitine acyltransferase (CAT), and the product of this reaction reacted with DPNH in the presence of $\mathrm{L}(+) \beta$-hydroxyacyl CoA dehydrogenase. These reactions are shown in Equations $2 \mathrm{a}$ and 2b.

$$
\begin{aligned}
& \text { AcAcCarn + CoA CAT AcAcCoA + Carnitine } \\
& \mathrm{AcAcCoA}+\mathrm{DPNH}+\mathrm{H}^{+} \underset{\text { Dehydrogenase }}{\mathrm{B}-\mathrm{OH} \text { ButCoA }} \\
& \beta \text {-OHButCoA + } \mathrm{DPN}^{+}
\end{aligned}
$$

If the original extract of peak 2 contained acetoacetylcarnitine, then the acyl CoA-carnitine acyltransferase would have converted it to acetoacetyl CoA in the presence of coenzyme A ( $c f$.
Equation 2a). We have found that the conversion of acetoacetyl $\mathrm{CoA}$ to acetoacetylcarnitine takes place at about $20 \%$ of the rate at which acetyl $\mathrm{CoA}$ is converted to acetylcarnitine. This is shown in Table IV. The transferase had minimal thiolase activity (Table V). When the above assay was carried out using acetoacetyl $\mathrm{CoA}$ and $\mathrm{C}^{14}$-methyl-labeled carnitine, and the products of the reaction chromatographed as in Figure 1, the same two radioactive peaks were found as in Figure 1. Peak 1 was again identified as carnitine. Peak 2 had an $R_{f}$ of about 0.60 and was free of carnitine. On alkaline hydrolysis of peak 2 , both free carnitine and acetoacetic acid $\left(R_{f}\right.$ 0.75 ) were found.

The acetoacetyl CoA produced from acetoacetylcarnitine was identified by conversion to $\mathrm{L}(+) \beta$-hydroxybutyryl CoA by the specific 
$\mathrm{L}(+) \beta$-hydroxyacyl CoA dehydrogenase (Equation $2 \mathrm{~b})(25)$ in the presence of DPNH. $\mathrm{L}(+)$ $\beta$-hydroxyacyl CoA dehydrogenase was only minimally contaminated with thiolase activity (Table $\mathrm{V})$. The over-all reaction sequence (Equations $2 \mathrm{a}$ and $2 \mathrm{~b}$ ) is summarized in Table VI. As has been previously mentioned, coenzyme $A$ and its derivatives remain at the origin in the thin-layer chromatographic separation of these compounds from peak 2 . $\mathrm{L}(+) \beta$-hydroxybutyryl CoA production was followed in two ways: 1) decrease in optical density at $340 \mathrm{~m} \mu$ (Equation $2 \mathrm{~b}$ ) and 2) formation of the hydroxamic acid derivative of $\beta$-hydroxybutyryl CoA. This was done by the addition of $500 \mu$ moles of salt-free hydroxylamine to the reaction shown in Equation $2 \mathrm{~b}$. The reaction was incubated for 30 minutes at $37^{\circ}$, dried, and extracted with $n$-butanol. The hydroxamic acid derivatives were chromatographed in two solvent systems ( $n$-butanol: ammonia: water) $(10: 1: 9)(32)$, and methylene chloride: $n$-butanol: acetic acid: water $(8: 2: 1.5: 3)(33)$. The chromatograms were sprayed with $\mathrm{FeCl}_{3}$, and the violet colored spots of the hydroxamates of $\beta$-hydroxybutyric and acetic acids were visualized. $\beta$-hydroxybutyrylhydroxamic and acetylhydroxamic acids were run as standards.

The DPNH oxidation corresponded to the formation of $0.26 \mu$ mole of acetoacetylcarnitine, which represented $4.3 \%$ of the total $\mathrm{C}^{14}$-carnitine

TABLE IV

Acetyl CoA and acetoacetyl CoA as substrates for Acyl CoA-carnitine acyltransferase*

\begin{tabular}{ccc}
\hline \hline & \multicolumn{2}{c}{$\begin{array}{c}\text { moles sulfhydryl group } \\
\text { produced/5 minutes }\end{array}$} \\
\cline { 2 - 3 } $\begin{array}{c}\text { Substrate } \\
\text { Concentration }\end{array}$ & Acetyl CoA & Acetoacetyl CoA \\
\hline$m \mu$ moles & & \\
50 & 0.117 & 0.028 \\
100 & 0.250 & 0.053 \\
150 & 0.310 & 0.078
\end{tabular}

* The reaction mixtures contained the indicated amounts of acetyl CoA or acetoacetyl CoA, $30 \mathrm{~m} \mu$ moles of DLcarnitine, $150 \mu$ moles of Tris- $\mathrm{HCl}$ buffer, $\mathrm{pH} 7.6,100 \mathrm{~m} \mu-$ moles of $5,5^{\prime}$-dithiobis-2-nitrobenzoic acid (38), and 0.15 $\mathrm{mg}$ of acyl CoA-carnitine acyltransferase. Final reaction volumes were $0.80 \mathrm{ml}$. Reactions were run at $30^{\circ}$ for 15 minutes. Final absorbency changes at $412 \mathrm{~m} \mu$ were obtained by subtracting absorbency changes in reference curvettes lacking carnitine from total absorbency changes. The initial velocities (first 2 minutes) were used for the calculation of the production rate of coenzyme $A$ (sulfhydryl groups).
TABLE $V$

$\beta$-ketothiolase activity of Acyl CoA-carnitine acyltransferase and $L(+) \beta$-hydroxyacyl Co $A$ dehydrogenase*

\begin{tabular}{|c|c|c|}
\hline \multirow[b]{3}{*}{ Reactions } & \multicolumn{2}{|c|}{$\mu$ moles DPNH oxidized } \\
\hline & \multicolumn{2}{|c|}{$\begin{array}{c}0.2 \mathrm{mg} L(+) \beta \text {-hydroxyacy } \\
\text { CoA dehydrogenase } / 20 \\
\text { minutes }\end{array}$} \\
\hline & pH 7.6 & pH 6.5 \\
\hline \multirow{2}{*}{$\begin{array}{l}\text { 1. Acetyl CoA } \\
\text { 2. Acetylcarnitine } \\
+\mathrm{CAT}+\mathrm{CoA} \\
\text { 3. Acetoacetyl CoA }\end{array}$} & 0.037 & 0.028 \\
\hline & $\begin{array}{l}0.029 \\
12.8\end{array}$ & $\begin{array}{l}0.019 \\
11.3\end{array}$ \\
\hline
\end{tabular}

* The reaction mixtures all contained $50 \mu$ moles potassium phosphate buffer, pH 7.6 or $6.5,0.2 \mu$ mole DPNH, 5 $\mu$ moles magnesium chloride, and $0.1 \mathrm{mg} \mathrm{L}(+) \beta$-hydroxyacyl CoA dehydrogenase. Reaction 1 contained $0.5 \mu$ mole acetyl CoA. Reaction 2 contained $0.5 \mu$ mole acetylcarnitine, $0.5 \mu$ mole coenzyme A, and $0.26 \mathrm{mg}$ carnitine acyltransferase (CAT). Reaction 3 contained $0.26 \mu$ mole acetoacetyl CoA. Final reaction volumes were $1.0 \mathrm{ml}$. Incubations were at $25^{\circ}$ for 5 minutes. Decrease in optical density at $350 \mathrm{~m} \mu$ was followed. Initial velocities of the reactions (first 2 to 3 minutes) were used to calculate reaction rates.

used in the reaction and about $40 \%$ of the radioactivity in peak 2 . The hydroxamates formed were found to have $R_{\mathbf{f}}$ 's of 0.20 and 0.13 in the butanol:ammonia solvent system and 0.35 and 0.68 in the methylene chloride: butanol:acetic acid system. These were identical with those of

TABLE VI

Enzymatic detection of acetoacetylcarnitine*

\begin{tabular}{|c|c|}
\hline Reaction & $\begin{array}{c}\text { DPNH } \\
\text { oxidized }\end{array}$ \\
\hline & umoles/ \\
\hline & 20 minutes \\
\hline 1. Complete & 0.26 \\
\hline 2. - C14-peak 2 & 0.016 \\
\hline 3. $-\mathrm{CoA}$ & 0.012 \\
\hline 4. -CAT & 0.004 \\
\hline 5. $-\mathrm{DPNH}$ & 0.008 \\
\hline 6. $-\mathrm{L}(+) \beta$-hydroxyacyl CoA dehydrogenase & 0.007 \\
\hline
\end{tabular}

* Reaction mixture $2 \mathrm{a}$ contained $0.66 \mu$ mole of C14-carnitine derivative that had been extracted from peak $2,1.0 \mu$ mole reduced coenzyme $\mathrm{A}, 100 \mu$ moles of Tris- $\mathrm{HCl}$ buffer, $\mathrm{pH} 8.0$, and $0.26 \mathrm{mg}$ of acyl CoAcarnitine acyltransferase (specific activity, $0.68 \mu$ mole per mg protein). Final reaction volume was $1.2 \mathrm{ml}$. The incubation was at $27^{\circ}$ for 5 minutes. The reaction was terminated by the addition of $0.1 \mathrm{ml}$ of $20 \%$ trichloroacetic acid and the precipitated protein removed by centrifugation. The supernatant was brought to $\mathrm{pH} 6.5$ with $\mathrm{KO}$

in reaction $2 \mathrm{~b}$. The final supernatant volume was $1.8 \mathrm{ml}$. Reaction $2 \mathrm{~b}$ contained $0.5 \mathrm{ml}$ of the neutralized supernatant from reaction $2 \mathrm{a}, 50 \mu$ moles potassium phosphate buffer, $\mathrm{pH} 6.5,0.2 \mu$ mole FPNH, and $0.2 \mathrm{mg}$ of $\mathrm{L}(+) \beta$-hydroxyacyl CoA dehydrogenase. 20 minutes. The change in optical density at $340 \mathrm{~m} \mu$ was recorded. 20 minutes. The change in optical density at $340 \mathrm{~m} \mu$ was recorded. Controls on the over-all conversion of the Cli-carnitine extract of peak 2 to $\beta$-hydroxybutyryl CoA consisted of : 1 ) the omission of the C14-carnitine peak 2 extract, coenzyme A or acyl CoA-carnitine acyl-
transferase (CAT) in reaction $2 \mathrm{a}$, and 2 ) the omission of DPNH of $L(+) \beta$-hydroxyacyl CoA dehydrogenase in reaction $2 \mathrm{~b}$. 
TABLE VII

Effect of carnitine on the conversion of pyruvate-2-C $\mathrm{C}^{14}$ to $\mathrm{CO}_{2}$ acetylcarnitine and long-chain fatty acids*

\begin{tabular}{|c|c|c|c|}
\hline Reaction & $\mathrm{C}^{14} \mathrm{O}_{2}$ & $\begin{array}{l}\text { C14-ace- } \\
\text { tylcarni- } \\
\text { tine }\end{array}$ & $\begin{array}{l}\text { C14-fatty }^{14} \\
\text { acids }\end{array}$ \\
\hline & $c p m$ & $c p m / m g$ & $c p m$ \\
\hline 1a. Pyruvate-2-C14 & 31,275 & 138 & $3 ; 820$ \\
\hline 1b. Pyruvate +carnitine & 23,090 & 388 & 8,370 \\
\hline 2a. Pyruvate-2-C14 & 16,715 & 96 & 2,020 \\
\hline 2b. Pyruvate +carnitine & 14,250 & 172 & 3,860 \\
\hline 3a. Pyruvate-2-C14 & 38,670 & 112 & 5,170 \\
\hline 3b. Pyruvate + carnitine & 33,590 & 260 & 9,675 \\
\hline
\end{tabular}

* The reaction mixtures contained $10 \mu$ moles of pyruvate-2-C14 $(200,000 \mathrm{cpm}), 10 \mu$ moles glucose-6-phosphate, $1 \mu$ mole TPN, and between 21 and $33 \mathrm{mg}$ of fed guinea pig liver homogenate in $2 \mathrm{ml}$ of calcium-free Krebs-Ringer phosphate buffer, $\mathrm{pH} 7.4$. Five $\mu$ moles of cium-free Krebs-Ringer phosphate buffer, $\mathrm{pH} 7.4$. Five $\mu$ moles of $2.5 \mathrm{ml}$. Incubations were at $37^{\circ}$ for 1 . Final reaction volumes were . 33 m $3 \mathrm{a}$ and $3 \mathrm{~b}$.

chemically prepared standards of $\beta$-hydroxybutyrylhydroxamate and acetylhydroxamate.

These data show that acetoacetylcarnitine was demonstrable in the fasted liver preparation in which carnitine stimulates acetoacetate production.

Carnitine and long-chain fatty acid synthesis. In liver homogenates from fed animals exogenous carnitine increased the conversion of pyruvate-2$\mathrm{C}^{14}$ to long-chain fatty acids and to acetylcarnitine, whereas it decreased the oxidation to $\mathrm{C}^{14} \mathrm{O}_{2}$ (Table VII). Both the conversion of pyruvate to acetyl $\mathrm{CoA}$ and the oxidation of acetyl $\mathrm{CoA}$ to $\mathrm{CO}_{2}$ occur within the mitochondria, whereas the bulk of long-chain fatty acid synthesis from acetyl CoA is extramitochondrial (10). Thus carnitine increased the utilization of acetyl CoA in the extramitochondrial compartment of the cell and decreased its intramitochondrial use. This would support a transport function role of carnitine in moving activated acetyl groups across the mitochondrial barrier as acetylcarnitine $(2,5)$.

\section{Discussion}

The data presented suggest that carnitine plays a central role in acetoacetate production and longchain fatty acid synthesis.

Carnitine augmented the production rate of acetoacetate in fasted guinea pig liver homogenates with a decrease in specific activity, whereas it increased the acetoacetate production rate in fasted guinea pig liver mitochondria with no change in specific activity. These data might be explained by consideration of the role of carnitine in long-chain fatty acid metabolism proposed by Fritz and Yue (1). These investigators postulated that the carnitine-induced stimulation of long-chain fatty acid oxidation and acetoacetate formation (11) was the result of a translocation of long-chain fatty acyl derivatives of carnitine from extra- to intramitochondrial sites. Thus, the effect of carnitine on the fasted homogenate with its abundant unlabeled extramitochondrial triglycerides would be to make more unlabeled acetoacetate by effecting an increased rate of movement of unlabeled long-chain fatty acids into the mitochondria. The mitochondrial preparation, with only small amounts of unlabeled triglyceride to serve as endogenous substrate, undergoes little change in specific activity.

The stimulatory effect of carnitine on the rate of conversion of pyruvate-2- $\mathrm{C}^{14}$ to acetoacetate in the fasted homogenate and mitochondria, and to long-chain fatty acids in the fed homogenate, could be explained by the postulated role of carnitine in short-chain fatty acid metabolism. Norum and Bremer (2) and Fritz and Yue (5) have postulated that acetyl CoA formed within the mitochondria is converted to acetylcarnitine by the acyl CoA-carnitine acyltransferase in the presence of carnitine, and that acetylcarnitine is transported out of the mitochondria. Outside the mitochondria acetyl CoA is regenerated from acetylcarnitine $(5,6)$. This carnitine-stimulated transport of short-chain acyl groups out of the mitochondria could have occurred in both fed and fasted liver preparations. In the fed homogenate the extramitochondrial enzymes of long-chain fatty acid synthesis convert the translocated acetyl CoA to long-chain fatty acids. In the fasted liver homogenate fatty acid synthesis is depressed and acetoacetate production is increased. The stimulatory effect of carnitine on the mitochondrial conversion of pyruvate- $2-\mathrm{C}^{14}$ to acetoacetate, and the detection of acetoacetylcarnitine in the reaction mixture, raised a question concerning the locus of action of the carnitine stimulation of acetoacetate production.

$\gamma$-Butyrobetaine, a competitive inhibitor of carnitine, markedly depressed acetoacetate production. The site of the inhibition could have been either on the movement of long-chain fatty acids 
into the mitochondria or on the movement of acetoacetylcarnitine out of the mitochondria. Since Fritz has shown that $\gamma$-butyrobetaine inhibits the short-chain carnitine transferase (23) and Bressler and Friedberg have demonstrated this inhibition effect on the long-chain carnitine transferase (4), the locus of action of carnitine is not known with certainty, but might be on both systems.

The detection of acetoacetylcarnitine in the reaction mixture in which carnitine stimulated acetoacetate production raises the question of whether acetoacetyl CoA must be transported out of the mitochondria to be converted to acetoacetate. Two pathways have been demonstrated for the production of acetoacetic acid from acetoacetyl CoA. Lynen and co-workers (34) have proposed a pathway known as the "HMG shunt." In this two-stage sequence acetoacetyl $\mathrm{CoA}$ condenses with acetyl CoA in the presence of a specific condensing enzyme to form $\beta$-hydroxy- $\beta$-methyl glutaryl CoA (HMG CoA). The HMG CoA is cleaved by a specific cleavage enzyme to acetyl $\mathrm{CoA}$ and acetoacetate. Although the cleavage enzyme is predominantly mitochondrial, the condensing enzyme is in high concentration in the microsomes (35). Stern, Drummond, Coon, and del Campillo (36) and Segal and Menon (37) have presented evidence in support of a direct deacylation of acetoacetyl $\mathrm{CoA}$ to acetoacetate by a mitochondrial deacylase. Because of the great difficulty in complete separation of fractions by means of centrifugation procedures, the exact functional sites of these enzymes are not definitely known. The transport of acetoacetyl CoA out of the mitochondria as acetoacetylcarnitine could be a prerequisite for acetoacetate formation. Such a situation would exist if 1 ) the HMG CoA condensing enzyme was predominantly extramitochondrial and so needed extramitochondrial acetoacetyl CoA or 2) the deacylation of acetoacetyl $\mathrm{CoA}$ occurred on the mitochondrial membrane.

\section{Summary}

Carnitine increased acetoacetate production in liver homogenates and mitochondria from fasted guinea pigs and stimulated the conversion of pyruvate to long-chain fatty acids in homogenates from fed guinea pigs. $\gamma$-Butyrobetaine, a com- petitive inhibitor of carnitine, markedly depressed acetoacetate production in the fasted preparation. The role of carnitine in the transport of long-chain fatty acyl CoA derivatives into, and short-chain fatty acyl CoA derivatives out of, the mitochondria is discussed.

\section{References}

1. Fritz, I. B., and K. T. N. Yue. Long-chain carnitine acyltransferase and the role of acylcarnitine derivatives in the catalytic increase of fatty acid oxidation induced by carnitine. J. Lipid Res. 1963, 4, 279.

2. Norum, K. R., and J. Bremer. Acyl coenzyme A as an intermediate in the mitochondrial acylation of carnitine by $\alpha$-keto acids. Biochim. biophys. Acta. (Amst.) 1963, 78, 77.

3. Bremer, J. Carnitine in intermediary metabolism. Reversible acetylation of carnitine by mitochondria. J. biol. Chem. 1963, 237, 2228.

4. Bressler, R., and S. J. Friedberg. The effect of carnitine on the rate of palmitate incorporation into mitochondrial phospholipids. J. biol. Chem. 1964, 239, 1364.

5. Fritz, I. B., and K. T. N. Yue. Effects of carnitine on acetyl-CoA oxidation by heart muscle mitochondria. Amer. J. Physiol. 1964, 206, 531.

6. Norum, K. The organ and cellular distribution of acetylcarnitine-CoA acetyltransferase. Acta chem. scand. 1963, 17, 896.

7. Lowenstein, J. M. The Supply of Precursors for the Extramitochondrial Synthesis of Fatty Acids, in the Control of Lipid Metabolism, J. K. Grant, Ed. London, Academic Press, 1963, p. 57.

8. Kornberg, A., and W. E. Pricer, Jr. Enzymatic synthesis of the coenzyme A derivatives of longchain fatty acids. J. biol. Chem. 1953, 204, 329.

9. Kennedy, E. P., and A. L. Lehninger. Oxidation of fatty acids and tricarboxylic acid cycle intermediates by isolated rat liver mitochondria. J. biol. Chem. 1949, 179, 957.

10. Wakil, S. J. Mechanism of fatty acid synthesis. J. Lipid Res. 1961, 2, 1.

11. Fritz, I. B. Action of carnitine on long chain fatty acid oxidation by liver. Amer. J. Physiol. 1959, 197, 297.

12. Schneider, W. C., and G. H. Hogeboom. Cytochemical studies of mammalian tissues: the isolation of cell components by differential centrifugation. A review. Cancer Res. 1951, 11, 1.

13. Walker, P. G. A colorimetric method for the estimation of acetoacetate. Biochem. J. 1954, 58, 699.

14. Sauer, F. Acetoacetate and $\beta$-hydroxy- $\beta$-methyl glutaryl coenzyme A metabolism in normal and ketotic guinea pigs. Canad. J. Physiol. 1961, 39, 1635 . 
15. Wakil, S. J., J. W. Porter, and D. M. Gibson. Studies on the mechanism of fatty acid synthesis. I. Preparation and purification of an enzyme system for reconstruction of fatty acid synthesis. Biochim. biophys. Acta (Amst.) 1957, 24, 453.

16. Bressler, R., and S. J. Friedberg. Substrate specificity of the fatty acid oxidase in the heart. Arch. Biochem. 1964, 104, 427.

17. Skipski, V. P., R. F. Peterson, and M. Barclay. Separation of phosphatidyl ethanolamine, phosphatidyl serine, and other phospholipids by thinlayer chromatography. J. Lipid Res. 1962, 3, 467.

18. Bremer, J. Carnitine in intermediary metabolism. The metabolism of fatty acid esters of carnitine by mitochondria. J. biol. Chem. 1962, 237, 3628.

19. Folch, J., I. Ascole, M. Lees, W. A. Meath, and F. N. LeBaron. Preparation of lipide extracts from brain tissue. J. biol. Chem. 1951, 191, 833.

20. Van Handel, E., and D. B. Zilversmit. Micromethod for the direct determination of serum triglycerides. J. Lab. clin. Med. 1957, 50, 152.

21. Gornall, A. G., C. J. Bardawill, and M. M. David. Determination of serum proteins by means of the biuret reaction. J. biol. Chem. 1949, 177, 751.

22. Hawk, P. B., B. L. Oser, and W. H. Summerson. Practical Physiological Chemistry. New York, McGraw-Hill, 1954, p. 880.

23. Fritz, I. B., S. K. Schultz, and P. A. Srere. Properties of partially purified carnitine acetyltransferase. J. biol. Chem. 1963, 238, 2509.

24. Stern, J. B. $\beta$-Ketothiolase in Methods in Enzymology, S. P. Colowick and N. O. Kaplan, Eds. New York, Academic Press, 1955, vol. 1, p. 581.

25. Wakil, S. J., D. E. Green, S. Mii, and H. R. Mahler. Studies on the fatty acid oxidizing system of animal tissues. VI. $\beta$-Hydroxyacyl coenzyme A dehydrogenase. J. biol. Chem. 1954, 207, 631.

26. Olah, G. A., and S. J. Kuhn. Organic fluorine compounds. XXVI. Acetoacetyl fluoride. J. org. Chem. 1961, 26, 225.
27. Wakil, S. J., and R. Bressler. Studies on the mechanism of fatty acid synthesis. $\mathrm{X}$. Reduced triphosphopyridine nucleotide-acetoacetyl coenzyme A reductase. J. biol. Chem. 1962, 237, 687.

28. Scow, R. O., and S. S. Chernick. Hormonal control of protein and fat metabolism in the pancreatectomized rat. Recent Progr. Hormone Res. 1960, 16, 497.

29. Fraenkel, G., and S. Friedman. Carnitine. Vitam. and Horm. 1957, 15, 73.

30. Fritz, I. B. Carnitine and its role in fatty acid metabolism. Advanc. Lipid Res. 1963, 1, 285.

31. Marquis, N. R., and I. B. Fritz. Enzymological determination of free carnitine concentrations in rat tissues. J. Lipid Res. 1964, 5, 184.

32. Stansly, P. G., and H. Beinert. Synthesis of butyryl coenzyme $A$ by reversal of the oxidative pathway. Biochim. biophys. Acta (Amst.) 1953, 11, 600.

33. Kumar, S., and R. M. Avena. Paper chromatographic separation of acetyl and $\beta$-hydroxybutyryl hydroxamates. Analyt. Biochem. 1963, 5, 265.

34. Lynen, F., U. Henning, C. Bublitz, B. Sörbo, and L. Kröplin-Rueff. Der chemische Mechanisms der Acetessigsäurebildung in der Leber. Biochem. Z. 1958, 330, 269.

35. Bucher, N. L. R., P. Overath, and F. Lynen. $\beta$-Hydroxy- $\beta$-methylglutaryl coenzyme A reductase, cleavage and condensing enzymes in relation to cholesterol formation in rat liver. Biochim. biophys. Acta (Amst.) 1960, 40, 491.

36. Stern, J. R., G. I. Drummond, M. J. Coon, and A. del Campillo. Enzymes of ketone body metabolism. I. Purification of an acetoacetate-synthesizing enzyme from ox liver. J. biol. Chem. 1960, 235, 313.

37. Segal, H. L., and G. K. K. Menon. Evidence for the formation of acetoacetate by direct deacylation of acetoacetyl-CoA in liver mitochondria. Biochem. biophys. Res. Commun. 1960, 3, 406.

38. Ellman, G. L. Tissue sulfhydryl groups. Arch. Biochem. 1959, 82, 70. 